\title{
Teoria do ator-rede: irredutibilidade, simetria e os estudos em administração/organizações
}

\section{Actor-network theory: irredutibility, symmetry and studies in administration/organizations}

\author{
JOSÉ DE ARIMATÉIA DIAS VALADÃO* \\ JOSÉ RAIMUNDO CORDEIRO NETO** \\ JACKELINE AMANTINO DE ANDRADE***
}

\section{RESUMO}

A Actor Network-Theory (ANT) é uma perspectiva teórico-metodológica que vem sendo elaborada desde a década de 1980. Traduzida para o Brasil como Teoria do Ator-Rede (TAR), ela inverte teórica e empiricamente a lógica comumente empregada pelos estudos sociológicos. Assim, em vez de assumir elementos como poder, tamanho, estrutura, agência e outros (meta)construtos, como causas das transformações sociais e técnicas, a TAR os coloca como efeitos, isto é, como consequências temporárias de redes relacionais heterogêneas, que indistinguem puros elementos sociais ou técnicos. Face à crescente adoção da TAR nos estudos em administração/organizações brasileiros, o presente trabalho discute pressupostos ontológicos e epistemológicos, notadamente a irredutibilidade e a simetria, que devem ser considerados nas práticas científicas que lançam mão da TAR como lente teórico-metodológica. Além disso, aborda-se a questão da

* Universidade Federal de Lavras (UFLA). Professor do Departamento de Administração e Economia (DAE/UFLA); Coordenador do Programa de Pós-Graduação em Administração Pública (PPGAP/UFLA). arimateiavaladao@hotmail.com .

** Universidade Federal do Vale do São Francisco (UNIVASF. Professor do Curso de Administração da Universidade Federal do Vale do São Francisco (UNIVASF); Doutorando em Administração pelo Programa de Pós-Graduação em Administração (PROPAD/UFPE). cordeironneto@gmail.com .

*** Universidade Federal de Pernambuco (UFPE). Professora do Departamento de Administração da Universidade Federal de Pernambuco (UFPE); Professora do Programa de Pós-Graduação em Administração (PROPAD/UFPE). jackeline.amantino@gmail.com . 
operacionalização de pesquisas que empregam essa abordagem na exploração empírica de suas temáticas, discutindo-se um breve conjunto de artigos brasileiros que apresentam esforços dessa natureza. Ao final, busca-se explicitar as oportunidades de inovação nos estudos do campo de administração/organizações, a partir de investigações nas quais os pressupostos em discussão sejam adequadamente assimilados nas práticas de pesquisa.

Palavras-chave: Teoria do Ator-Rede. Irredutibilidade. Simetria. Administração. Organizações.

\section{Abstract}

The Actor-Network Theory (ANT) is a theoretical-methodological perspective that has been elaborated since the 1980s. Translated into Brazil as Teoria do Ator-Rede (TAR), it theoretically and empirically inverts the logic commonly employed by sociological studies. Thus, instead of assuming elements such as power, size, structure, agency, and other (meta) constructs, as causes of social and technical transformations, TAR places them as effects, that is, as temporary consequences of heterogeneous relational networks, pure social or technical elements. In view of the increasing adoption of TAR in studies in Brazilian administration/organizations, this paper discusses ontological and epistemological assumptions, notably irreducibility and symmetry, which should be considered in the scientific practices that use TAR as a theoretical and methodological lens. In addition, it addresses the question of the operationalization of research that employ this approach in the empirical exploration of its themes, discussing a brief set of Brazilian articles that present efforts of this nature. In the end, it is sought to make explicit the opportunities of innovation in the studies of the field of administration/organizations, from investigations in which the assumptions under discussion are properly assimilated in the research practices.

Key-words: Actor-Network Theory. Irreducibility. Symmetry. Management. Organizations.

\section{INTRODUÇÃo}

A Teoria do Ator-Rede (TAR) é uma perspectiva teórico-metodológica que vem sendo elaborada desde a década de 1980 (LAW, 2007). Entre as correntes teóricas que influenciaram seus primeiros 
trabalhos estão a Semiótica Greimasiana (GREIMAS; COURTÉS, 1979); as Filosofias de Gilles Deleuze (DELEUZE; GUATTARI, 1987) e Michel Serres (SERRES, 1990; 1996); os Sistemas Tecnológicos de Thomas Hughes (HUGHES, 1983, 1987); a Sociologia de David Bloor (BLOOR; 2009) e a Etnometodologia de Harold Garfinkel (GARFINKEL, 1967).

A partir de seus trabalhos pioneiros (LATOUR; CALLON, 1981; CALLON, 1986; LATOUR, 1988a; LAW, 1986), cada vez mais essa abordagem se constituiu numa linha de investigação que ficou conhecida inicialmente na França como Acteur Reseau e se consolidou na língua inglesa como Actor-Network Theory (ANT). Traduzida para o Brasil como Teoria do Ator-Rede, a TAR, teórica e empiricamente, inverte a lógica comumente empregada pelos estudos e, ao invés de atribuir a elementos como poder, tamanho, estrutura, agência e outros (meta)construtos a responsabilidade das causas das transformações sociais e técnicas, os coloca como efeitos, isto é, como consequências temporárias de redes relacionais heterogêneas que indistinguem puros elementos sociais ou técnicos.

No campo da pesquisa em Administração, tem havido um crescente interesse pela perspectiva da TAR, desde que a emergência de novas abordagens nas ciências humanas - notadamente a partir do final do século $X X$ - têm sido percebidas como oportunas para a superação de dilemas recorrentes na área (LEE; HASSARD, 1999; CZARNIWASKA, 2009b; HASSARD; COX, 2013). Assim, o emprego da TAR tem apresentado uma adesão cada vez maior nesse campo, seja em áreas específicas como os estudos organizacionais (FELDMAN; ORLIKOWSKY, 2011), seja em outros campos relacionados à gestão, como administração pública (ARNABOLDI; AZZONE, 2010) e tecnologias (ORLIKOWSKY; SCOTT, 2008). Mesmo em segmentos como os estudos organizacionais críticos, certa aproximação tem sido percebida por alguns pesquisadores que defendem que a conexão entre essas perspectivas guarda elevado potencial de renovação para ambas (ALCADIPANI; HASSARD, 2010).

No Brasil, o emprego da TAR em pesquisas da área de Administração pode ser observado sobretudo a partir dos anos 2000. São exemplos os trabalhos como o de Andrade (2006) sobre a gestão de políticas públicas; de Tureta e Alcadipani (2011) e Tureta e Araújo 
(2013) em sua investigação acerca dos processos organizacionais em escolas de samba; de Andrade (2011), que trata de redes de patentes em biotecnologia; de Andrade, Cordeiro Neto e Valadão (2013) sobre iniciativas em gestão do desenvolvimento; de Tonelli e Zambalde (2015), a respeito do fenômeno do empreendedorismo tecnológico vinculado a instituições de pesquisa; de Cerreto e Domenico (2015) ao fazer uso da TAR para estudar um processo de mudança organizacional; de Valadão, Cordeiro Neto e Andrade (2017) em sua abordagem acerca da expansão de uma tecnologia social de educação rural.

Além desses trabalhos, que possuem uma orientação para a exploração de questões empíricas, outros trabalhos de autores brasileiros têm se dedicado a refletir teoricamente sobre o uso da TAR na área de administração ou a propor articulações teóricas entre esse movimento intelectual e outras abordagens mais comuns na área. Nessa perspectiva, podem-se citar Andrade (2004); Alcadipani e Tureta (2009); Cavalcanti e Alcadipani (2013); Camillis e Antonello (2015); Camillis, Bussular e Antonello (2016); Duarte e Alcadipani (2016) e Tonelli (2016).

Nesse cenário, o presente artigo compartilha do entusiasmo relacionado a essa expansão da TAR como inspiração para estudos na área de Administração, especialmente por proporcionar renovadas formas de lidar com questões como a relacionalidade, com o debate sobre as perspectivas micro e macro e com a discussão a respeito da estrutura-agência (CORDEIRO NETO; VALADÃO; ANDRADE, 2016). Aqui, a discussão está direcionada para um aprofundamento de dois dos principais pressupostos presentes na TAR, quais sejam: o princípio da irredutibilidade e o princípio da simetria, os quais se mostram fundamentais para o posicionamento das estratégias de investigação ator-rede, em termos ontológicos e epistemológicos.

Nas próximas seções, com o objetivo de contribuir para uma maior clareza quanto às implicações desses pressupostos no trabalho do pesquisador que venha a empregar a TAR como orientação teórico-metodológica, a abordagem é apresentada em termos gerais e, em seguida, cada um desses pressupostos é explorado separadamente (seção 2). Na sequência, são exibidos estudos brasileiros recentes que têm procurado equacionar tais implicações em suas estratégias de 
investigação no campo das pesquisas em Administração. Para tanto, cinco pesquisas são destacadas para esse propósito e brevemente discutidas (seção 3). Por fim, algumas considerações finalizam o trabalho, enfatizando elementos que se mostram centrais na tarefa da pesquisa em administração quando da opção teórico-metodológica pela Teoria do Ator-Rede (seção 4).

\section{Pressupostos DA TEORIA do ATOR-REDE}

A TAR, de um modo geral, trata dos vínculos e relações entre atores e as redes que os caracterizam. Mas não vínculos sociais como é discutido na Sociologia, pois para Latour (2012), a TAR pode ser considerada a "sociologia das associações de coletivos" ao invés de ocupar-se da sociedade. O coletivo se refere às associações de pessoas, materiais, textos e todos os demais atores envolvidos em relações sociotécnicas e que delineiam redes únicas e específicas, mesmo sendo, às vezes, de forma provisória. Enquanto o conceito de sociedade implica uma prévia distinção entre natural e social, o coletivo não "remete a uma unidade já feita, mas a um procedimento para coligar as associações de humanos e não-humanos" (LATOUR, 2004a, p. 373, grifos do autor). No coletivo, não é possível supor que serão os humanos quem determinarão os efeitos das redes. A ideia de agência, nesse sentido, é compreendida como ação distribuída nas redes, deslocando a ênfase das questões de intencionalidade e da busca por desvelar origens e fontes da ação. A incerteza quanto às fontes da ação, desse modo, é incentivada como recurso teórico-metodológico, enfatizando o ator como ator-rede pela sua multiplicidade, que "não é a fonte de um ato e sim o alvo móvel de um amplo conjunto de entidades que enxameiam em sua direção" (LATOUR, 2012, p. 75).

A sociedade, para TAR, não é somente um "conjunto de pessoas em um sistema de organização coletiva" (DICIONÁRIO AULETE DIGITAL, 2013). Os seres humanos formam uma rede (social) apenas mediante a presença e ação de materialidades diversas. Em outras palavras, essas associações seriam insustentáveis caso tivessem que ser suportadas somente por "elementos sociais" (LAW; MOL, 1995). Na visão da TAR, são inadequadas as explicações convencionais das Ciências Sociais, que se se concentram nos humanos e secundarizam 
a presença dos objetos ou, por sua vez, focalizam nas tecnologias e separam em planos diferentes os humanos e os materiais implicados nas relações estudadas. A divisão ontológica entre os humanos e não humanos pressuposta nesses estudos é, para a TAR, uma das principais dificuldades de efetivamente revelar o "tecido" da qual a sociedade é formada.

Com a TAR, afirma-se que as pessoas não estabelecem suas relações por meio unicamente de seu corpo e mente. As relações "humanas" são definidas inextricavelmente na presença de materiais, em interações mais complexas do que as pressupostas pelos dualismos externo-interno e corpo-mente, motivo pelo qual Mol e Law (2004) sugerem a noção de corpo-em-ação, com limites semipermeáveis e uma configuração complexa. Os materiais, no entanto, só podem ser caracterizados a partir de sua interação com a presença humana. Isso faz de cada ser humano e de cada objeto "[...] um efeito produzido por uma rede de materiais interativos e heterogêneos" (LAW, 1992, p. 4). Essa rede heterogênea é ao mesmo tempo causa e consequência dessas interações. Os humanos e objetos atuam indissociadamente, formando-se em atores compósitos e irredutíveis a um corpo (humano) ou material isoladamente. Isso impossibilita separar humano e não humano em distintas posições ontológicas. As interações são muito mais sociomateriais do que estritamente sociais, significando que "socialidade e materialidade são conjuntamente construídas" (LAW; MOL, 1995, p. 274).

Por meio da expressão hifenizada "atores-redes", em oposição ao ator social necessariamente humano da tradição sociológica, a TAR tornou-se "[...] uma resposta à tendência da sociologia que coloca entre parênteses o não humano, seja ele tecnológico ou natural" (LEE; BROWN, 1998, p. 222) e o coloca no mesmo plano constituído pelos humanos. "Humanos podem, mas não necessariamente são, atores; atores podem, mas não necessariamente são, humanos" (LAW; MOL, 1995. p. 277). As organizações, por exemplo, comumente estudadas como meios instrumentais para que os humanos alcancem seus objetivos, passam a ser vistas na TAR, como redes ordenadas provisoriamente oriundas das relações e interações de atores redes em contínuos processos associativos e dissociativos. Organizações, por conseguinte, são tomadas como efeitos interati- 
vos, “[...] são mais ou menos papéis precariamente padronizados desempenhados por pessoas, máquinas, textos, prédios, e tudo o mais que possa oferecer resistência" (LAW, 1992, p. 384), ou ainda "uma realização, um processo, uma consequência, uma configuração de resistências, um efeito precário" (LAW, 1992, p. 390). Tanto as organizações como outros ordenamentos (como a família, um computador, a economia etc.) são, assim, estabilizações provisórias negociadas em extensas redes heterogêneas de pessoas, materiais e outros elementos, apresentando-se ora de maneira única, simples e estruturada, ora caótica, desordenada e complexa, em virtude dos diversos e diferentes deslocamentos dos atores na rede.

O que é comumente convencionado como social passa a ter outro sentido na TAR. O social, ao invés de ser compreendido como um conjunto de características que diferem os diversos grupos humanos (LATOUR, 2012), organizados independente e estruturalmente, deve ser entendido pelas suas raízes etimológicas e considerar o "socio", somente na perspectiva de "unir, associar, fazer ou ter em comum" (STRUM; LATOUR, 1987, p. 793). O social assemelha-se mais a um verbo (associar) do que a uma entidade absoluta (o social), apresentando-se no cotidiano das relações como processos e movimentos, nos quais a atuação dos atores pode ser compreendida e descrita (CALLON; LATOUR, 1981). Diferente de um social que explica as formações e conformações do mundo, o que se presencia cotidianamente são apenas efeitos temporários das interações dos atores. Para Law (1992), o natural, o técnico e o social, apesar de apresentarem cotidianamente separados e representados por atores que se parecem entidades absolutas, empiricamente nada mais são do que "redes de certos padrões de materiais heterogêneos" (LAW, 1992, p. 2).

O que é comumente denominado de realidade é, para a TAR, o resultado das convenções, interações e ações dos atores-redes e não uma existência dada a priori. São as negociações entre os atores que definem o que será duradouro ou provisório, rápido ou demorado, efêmero ou perene, local ou global, simples ou complexo, tomado como certo (real) ou construído. O real é o que resiste às negociações e permite ser identificado e localizado em uma rede de atores. A resistência que permite que algo seja considerado real, contudo, 
não é definitiva, ela está sempre em um contínuo entre estabilidade e mudança. Algumas coisas resistem às negociações e permanecem reais, outras perdem suas identidades e são continuamente transformadas. A realidade, para a TAR, são os "gradientes de resistência" das negociações e interações, ou seja, são as possibilidades de durabilidade dos vínculos estabelecidos pelos atores. Somente o que resiste e permanece rastreável pode ser considerado real (LATOUR, 1988a), com seus diferentes "gradientes de durabilidade" (LAW; MOL, 1995, p. 279).

Nas relações que definem esses gradientes de resistência não é possível pressupor que uns poucos atores agem enquanto os demais são passivamente transportados durante os descolamentos que delineiam a realidade. Nos estudos das Ciências Sociais, é comumente convencionado que alguns fazem uso da ação, produzindo inovações, técnicas, tecnologias e empreendimentos das mais diversas formas e muitos intermediários transportam os resultados dessas realizações (LATOUR, 1994a). Para esses estudos, os intermediários são consumidores passivos e dependentes das inovações. O que deve ser estudado são os produtores de inovações, pois eles são os geradores de mudanças e transformações sociais. Conceitualmente, um intermediário leva as causas a seus efeitos sem alterá-las, servindo apenas de meio de transporte, podendo ser definido como "aquilo que transporta significado ou força sem transformá-los" (LATOUR, 2012, p. 65).

No entendimento da TAR, para a condução dos gradientes resistivos da realidade, os atores que transportam as inovações são mediadores e não intermediários. Na mediação, o transporte é tão relevante quanto a inovação em si. A realidade é modificada e construída não somente quando uma inovação acontece, mas também quando ela é deslocada pelos diversos atores, agindo em redes complexas e em ligações permanentes. Como mediadores, os atores "transformam, traduzem, distorcem e modificam o significado ou os elementos que supostamente veiculam" (LATOUR, 2012, p. 65). Eles são "[...] dotados da capacidade de traduzir aquilo que eles transportam, de redefini-lo, desdobrá-lo, e também traí-lo" (LATOUR, 1994a, p. 80). As inovações e tudo o mais que é produzido pelas interações são deslocados pelos mediadores, cooperando nas 
mudanças mesmo com ações e práticas muitas vezes com significativas diferenças das originalmente concebidas.

Em consequência, não há somente fatos reais consumados e indiscutíveis, seja por uma realidade natural, seja por uma realidade construída. Há mais coisas na mediação do que fatos tomados como certos, ou como disse Latour (2012), há tanto "questões de fato" como "questões de interesse". As Ciências Sociais, geralmente, tratam das questões como se só houvesse questões de fato, ou seja, fatos puros e genuínos, sejam originários da natureza ou da sociedade, ignorando as infinitas questões de interesse ou híbridos quase-sujeitos ou quase objetos, dotados simultaneamente de elementos naturais e sociais, de objetividade e subjetividade. $\mathrm{O}$ âmbito de estudo da TAR, desse modo,

[...] é o estudo dos matters of concern [questões de interesse], a invenção de um certo empirismo - um segundo empirismo, digamos, que não tem a ver simplesmente com os objetos [questões de fato], no sentido tradicional do empirismo, mas com os matters of concern, com as coisas que constituem causas, em oposição aos objetos (LATOUR, 2004b, p. 398).

A TAR não compreende os atores como intermediários que simplesmente transportam fatos aparentemente fechados e sem controvérsia alguma. Os atores são mediadores que fazem de todo fato um interior incerto e que envolve continuamente diferentes atuações, interpretações, pontos de vista e transformações. A atuação dos mediadores faz que a realidade, mesmo claramente estabilizada e seus gradientes de resistência definidos, apresentando-se plenamente estabelecida, tenha sua unidade sempre pendente, pois a qualquer momento essa estabilidade pode ser retomada e colocada à prova. As questões de interesse que envolvem cada fato estabelecido no trabalho de mediação fazem que a verdade tenha existência provisória e incerta, precisando sempre ser considerada dentro da atuação dos mediadores que a transportam e negociam a sua validade continuamente. Como se observa nesta discussão introdutória, a Teoria do Ator-Rede compreende declarações com significativas implicações no âmbito da pesquisa em ciências sociais, não apenas 
em termos da operacionalização das práticas de investigação, mas imbricando questões ontológicas e epistemológicas. Tais questões serão aprofundadas a seguir, concentrando-se nos pressupostos da irredutibilidade e da simetria generalizada, marcadamente presentes na TAR.

\subsection{Irredutibilidade como Ontologia dos Atores-Rede}

Antes de ser discutida na TAR, a irredutibilidade já era um conceito muito presente na Filosofia. Na Teoria da Relatividade de Einstein, por exemplo, cada frame de referência era definido a partir do ponto de vista do observador, não podendo um frame ser comparado (reduzido) a outro (LATOUR, 1988b). Em Deleuze e Guattari (1988), a irredutibilidade já podia ser vista no seu tratado sobre nomadologia ao considerar a impossibilidade de comparar a máquina de guerra ao aparelho do Estado, já que ambos têm origens e naturezas diferentes um do outro. Foucault (1987) também visualizara no exercício do poder que os mecanismos de disciplina e o direito de soberania são tão heterogêneos quanto irredutíveis. Serres $(1995 ; 2000)$, por sua vez, condenava, como um todo, o gosto do pensamento moderno pela unidade. Para a TAR, em específico, é preciso generalizar e dizer que coisa alguma é redutível a outra.

O tipo de reducionismo contra o qual a TAR se impõe mais frontalmente pode ser compreendido como a própria separação entre "mundo social" e "mundo natural" (CALLON, 1986; LATOUR, 1994), conforme já discutido e que será mais aprofundado na seção sobre o pressuposto da simetria generalizada, mais adiante. É preciso, nessa direção, entender a oposição dessa abordagem às perspectivas de investigação que reduzem, aprioristicamente, o número de seres relevantes aos fenômenos estudados, mostrando-se sobremaneira indiferentes às distinções entre eles e os agregando em purificações, como sociedade e natureza. Tais abordagens reducionistas, em decorrência de suas insensibilidades às diferenças, permitem nomear poucas entidades como fontes causais de muitos efeitos, tratá-las a partir de padrões de comensurabilidade e agrupá-las a partir da consideração de supostas essências que as caracterizariam.

A discussão de irredutibilidade na TAR iniciou com Latour (1988a) ao estudar Pasteur e a sua prática de elaboração do pro- 
cesso de fermentação do ácido láctico. Latour considerou que as interações dos atores presentes na mistura do que ele chamou de "pasteurização da França" se deu de forma que eles nunca eram causas completas das transformações ocorridas, muito menos completas consequências (LATOUR, 2001). Não só os microrganismos, mas o próprio Pasteur foi transformado durante a passagem das completas gerações espontâneas de micróbios para a total existência do fermento (LATOUR, 2001). Se, por um lado, Pasteur descobriu os micróbios, por outro, os micróbios possibilitaram que Pasteur se tornasse um notório cientista. "Pasteur ajudou o fermento a mostrar quem era, o fermento "ajudou" Pasteur a ganhar uma de suas muitas medalhas" (LATOUR, 2001, p. 145). Os diversos artigos que vieram a público sobre esse processo de pasteurização, posteriormente, ajudaram a sedimentar o processo de construção do fermento láctico. A descoberta da pasteurização não pode ser vista como um processo único e específico, mas um trabalho de mediação que translada em redes de negociações, associações, dissociações, traições e muitas outras relações que tornam a pasteurização um processo único e não equiparável a qualquer outro na história da Química.

Ao estudar fatos como o processo de pasteurização, ao mesmo tempo em que se fundamentava em reflexões filosóficas como as de Foucault, Deleuze e Serres, Latour (1988a) percebeu que as teorias do conhecimento se baseavam em um postulado que essas filosofias, de uma maneira geral, criticavam. As teorias do conhecimento sempre partiram da certeza de que a força é uma grandeza de diferentes proporções, com alguns atores possuindo-as mais e outros menos. Além disso, havia sempre uma sobreposição do certo pelo duvidoso, devendo um ser assumido e buscado (verdade) e o outro rejeitado e eliminado a todo custo (dúvida) (LATOUR, 1988a). Ao analisar conceitos como conhecimento e poder, contudo, que eram até então fontes tomadas como certas das forças sociais e técnicas da Ciência Social, Latour (1988a) passa a entender que elas são também efeitos provisórios resultantes de negociações e interações entre atores, sendo impossível supor, a priori, por meio de quais forças e com que intensidades essas negociações são movidas. Isso leva a TAR a considerar a verdade e o erro com condições equivalentes nas interações, sendo a força uma variabilidade relevante somente 
se observada na interação em que ela ocorre, não fazendo sentido ser comparada a qualquer outra relação. Do contrário, a prática de promover comparações entre elementos presentes em distintas associações, torna-se possível apenas por meio do artifício das "medidas medidoras", as quais "constroem uma comensurabilidade que não existia antes que fossem desenvolvidas. Nenhuma coisa é, por si só, redutível ou irredutível a qualquer outra. Nunca por si mesma, mas sempre por intermédio de uma outra que a mede e transfere esta medida a coisa" (LATOUR, 1994, p. 111). Significa dizer que força é uma especificidade de cada aliança e irredutível a qualquer outra, sendo a comensurabilidade uma operação desempenhada por intermédio de outras entidades (medidas) e não uma propriedade das entidades em comparação.

Todo ator, por si só, é uma força a ser considerada (LATOUR, 1988a) e por menos evidente que seja, não pode ser julgado como menos significativo em comparação a outros. Todos os atores são concretos o suficiente para que sejam considerados em pé de igualdade nas alianças (HARMAN, 2009), não existindo um maior, melhor ou mais poderoso, exceto dentro de suas próprias relações. As alianças são os compromissos assumidos pelos atores, independentemente de suas posições e disposições, que definirão quais forças influenciarão nos caminhos a serem traçados e percorridos e que outras permanecerão inativas. A força é medida por intermédio unicamente da relação (LATOUR, 1994a), pois “existem múltiplos modos de ordenar, múltiplas realidades [em resistências simultâneas], e isto funciona precisamente porque todas são irredutíveis umas às outras" (LAW, 2007, p. 14).

Para pressupor uma realidade somente como gradientes de resistência específicos e nunca redutíveis a unidades estáveis e duradouras, há, implicitamente, quatro princípios que orientam essas pressuposições e dão validade à TAR (LATOUR, 1988a; HARMAN, 2009). Esses princípios são: a) a permanente presença de atores na definição e evidenciação da realidade; b) a própria ideia de irredutibilidade de que nada é, por si só, redutível a qualquer outra; c) a existência de translação sempre que houver vínculos entre os atores; e d) a ideia de que não há atividade e inatividade a priori, mas contínuas provas de força. 


\begin{abstract}
a) A permanente presença de atores na definição e evidenciação da realidade

O primeiro princípio pressupõe a realidade sempre sendo elaborada e performada pelos atores. “Átomos e moléculas são atores, assim como os filhos, os pingos de chuva, os trens bala, os políticos e os números. Todas as entidades estão exatamente na mesma posição ontológica" (HARMAN, 2009, p. 14). Os atores atuam e só podem ser vistos e caracterizados nessa atuação. Não há um núcleo substantivo que mantém uma essência de cada ator, se assim fosse, tiradas as deformações e os acidentes periféricos ocasionados pelas relações, tornaria possível localizar um núcleo essencial que o caracterizaria. Nesse caso, seria possível localizar em cada ator uma substância ou essência indivisível (HARMAN, 2009), o que faria a TAR abandonar seu posicionamento antiessencialista, que compreende os atributos presentes nos atores como decorrentes das relações em que estes se encontram e implicaria voltar às posições ontológicas empiristas ou construtivistas comumente adotadas como absolutas. Um ator, ao contrário, é uma
\end{abstract}

[...] absoluta concretude. Todo ator é simplesmente o que ele é. Isto implica que todos os atores estão na mesma posição. Tanto o grande como o pequeno, tanto o humano como o não-humano. Nenhum ator é somente base para outros; cada um cede ou resiste a outro de maneira muito específica. Por isso todo ator é inteiramente concreto, nós não encontramos sua realidade em alguma essência solitária ou substrato puro, mas sempre em um absoluto lugar específico no mundo, em alianças completamente específicas e em um dado momento (HARMAN, 2009, p. 15-16, tradução do autor).

Na perspectiva da irredutibilidade nenhum ator, a priori, é fraco o suficiente que não possa inscrever outro. Quando se juntam, as possibilidades de deslocamentos podem diferenciar-se. Com isso, um ator pode ganhar ou perder força em associação com outros, ganhar ou perder mobilidade, bem como, diversos atributos. Certos resultados de seu trabalho não podem voltar ao seu estado original. Além disso, como tudo é passível de ser negociado, não se pode dizer que um ator, ou uma associação deles, segue regras, leis ou 
estruturas, como também não se pode dizer que age sem elas (LATOUR, 1988a). A sua durabilidade é relativa e sua existência só pode ser considerada nas suas relações, podendo continuar, mudar, ou deixar de existir em cada novo evento dessas relações (HARAWAY, 1991; MOSER; LAW, 1999). Como os eventos são sempre específicos, pois "tudo acontece somente uma vez e em um único lugar" (LATOUR, 1988a, p. 162), os atores são gradientes irredutíveis de resistência que cooperam na composição da realidade.

\section{b) A própria ideia de irredutibilidade}

O segundo princípio é a própria ideia de irredutibilidade. A Ciência Social rotineiramente emprega um fato para explicar outro. $\mathrm{Ou}$ toma um como causa ou efeito de outro. Muitas vezes esse emprego de causa e efeito funciona, mas, muitas vezes, também não dá certo para igual número de casos. Para não continuar pagando o preço do risco e ter sempre que apostar na possibilidade do acerto, o melhor é começar a análise presumindo que nenhum objeto ou sujeito é redutível ou irredutível a qualquer outro (HARMAN, 2009). Ao invés de pressupor que um evento $A$ define um evento B ou C, ou que os eventos B e C definem e moldam o evento A, há que considerar que são concretudes que precisam ser analisadas como tais, sem reduzi-los, a priori, como causa ou consequência de nenhum outro. Afinal, essa pressuposição incorreria na exclusão de elementos presentes nas relações como itens irrelevantes para as características de um dado fenômeno, reduzindo as entidades assumidas como "causas" e ignorando os efeitos relacionais sobre os atributos presentes entre os atores.

Em outras palavras, conforme destaca Latour (2012, p. 37), "não devemos, de início, limitar o tipo de seres existentes no mundo social", pois "o nome do jogo não é a redução, mas 'irredução'. [...] o número de atores precisa ser aumentado; o leque de agências que levam os atores a agir, expandido" (LATOUR, 2012, p. 201). Há que se manter sempre certa relatividade entre a identidade, a equivalência e as trocas entre os atores, pois cada uma dessas tem um "custo" (LATOUR, 1988a, p. 162) que só pode ser conhecido estudando as relações entre eles. 
Pelo princípio da irredutibilidade, a abordagem da TAR mantém constante vigilância para não incorrer na imposição de restrições artificiais às explicações que devem ser buscadas nas práticas, considerando adequadamente a "metafísica prática" dos atores (LATOUR, 2012), sem fixar singularidades nem distinções/divisões como pontos de partidas, mas compreendo-as, quando empiricamente identificadas, como efeitos ou resultados (LAW, 1999). Isso também possibilita a sensibilidade às diferenças, amenizando o risco de forçar equivalências entre as entidades ou de supor grandes rupturas baseadas em uma única característica, na medida em que o que as distingue "não é um único abismo vertical entre mundos e o mundo, mas as inúmeras diferenças entre elas" (LATOUR, 2001, p. 164).

\section{c) A existência da translação}

A translação é o terceiro princípio que ajuda a definir a irredutibilidade afirmada na TAR. As operações de translação são compreendidas como parte fundamental das interações sempre em mudança contínua, nas quais o deslocamento está de contínuo em negociação pelos atores e seus aliados. A translação é cada deslocamento negociado que se traduz em novos links, conexões e redes. Ela designa "[...] uma operação generalizada, não apenas linguística, e toma muitas formas diferentes. Pode envolver o deslocamento de algo, ou o ato de substituição, mas sempre envolve transformação" (CZARNIAWSKA, 2009, p. 424, grifos do autor). Latour (1999, p. 32, grifos do autor) diz que usa translação para "[...] significar deslocamento, movimento, invenção, mediação, a criação de um link que não existia antes e que, em certa medida, modifica dois elementos ou agentes".

Pode-se compreender translação com a sua ênfase sobre a transformação, mudança, invenção, pela sua oposição à ideia de transporte (LATOUR, 2001; LATOUR, 2012), isto é, como movimento contrário ao movimento de deslocar sem alterações. Enquanto a noção de transportar implica assumir uma diversidade de agentes como meros intermediários que transportam causas, o recurso à concepção de transladar presume a existência de mediadores em coexistência, em conexões que engendram transformações. Nessa compreensão, reconhecer a translação proporciona abandonar o reducionismo de explicar muito por meio de poucos elementos causais 
e do rebaixamento de diversos agentes a simples intermediários, bem como, proporciona abertura para a identificação de novidades produzidas nas associações, visto que delas (e não de essências) emergem os atores e suas propriedades manifestas.

A translação diz respeito ao deslocar dos atores no trabalho de mediação. Para Callon (1986), além disso, a translação enfatiza a continuidade, os deslocamentos e as transformações que ocorrem nas muitas fases da história dos atores e em suas atuações como mediadores. Nesse sentido, Latour (2001, p. 106-107) compreende que "a operação de translação consiste em combinar dois interesses até então diferentes [...] num único objetivo composto" à medida que "o que importa nessa operação de translação não é unicamente a fusão de interesses que ela enseja, mas a criação de uma nova mistura"; uma mistura em que é impossível reconhecer, isoladamente, natureza e sociedade. O movimento contínuo, com isso, é o que assegura que nada, por si só, é igual ou diferente de qualquer coisa, pois não existe equivalência em princípio, apenas translações (LATOUR, 1988a, p. 162).

\section{d) Contínuas Provas de força}

Um último princípio da irredutibilidade que não pode deixar de ser mencionado envolve a ideia de força entre os atores. Estes não são mais fortes ou fracos em virtude de alguma força ou fraqueza inerente ou que os mesmos a possuem por meio de uma essência particular. Ao contrário, os atores ganham ou perdem forças somente por meio de alianças (HARMAN, 2009). Para Latour (1988a), não há uma força apriorística em si, mas há apenas estados de forças ou fraquezas definidos por essas alianças. Ou mais simplesmente, há apenas ensaios, pois as resultantes de suas forças são sempre provisórias e momentâneas. Uma força, assim, não pode ser reduzida a um ator ou grupo de atores sem considerar o trabalho que está sendo realizado para evidenciá-la. Ela pode somente ser testada, contada ou medida em determinados pontos e momentos da rede de atores, pois ela é sempre efeito provisório das alianças em que estes estão continuamente engajados no trabalho de mediação. Em consequência, nem a natureza possui forças inatas, nem a sociedade 
possui forças sociais puras, se elas existirem isso é devido às definições provisórias realizadas pelo trabalho de mediação, pois os mediadores são aqueles que definem quais forças serão empregadas e como elas serão distribuídas.

Desse modo, a impossibilidade de definir forças a priori implica não ser possível reduzir algo ou alguém a uma coisa pronta e acabada. Tudo deve ser conhecido e descrito pelo traçar da rede da qual atua, visto que por mais fracamente que um ator recrute outro, isto restringe a possibilidade de cada um definir suas próprias associações. Entre um traçar e outro da rede, bem como, entre uma força e outra, nada, por si só, pode ser comensurável ou incomensurável, por isso Latour afirma que nada é nem redutível nem irredutível em princípio, mas deve ser testado, contado e medido, a fim de evidenciar sua performance frente aos demais. É nesse sentido que a TAR pressupõe rede de atores, cada uma com suas respectivas forças, definindo o que será ou não sustentado como real. Os atores têm existência comprovada somente por meio de suas interações, pois "[...] quanto mais eles se afastam de suas relações, menos reais eles se tornam" (HARMAN, 2009, p. 19). Por conseguinte:

[...] realidade, como indica a palavra latina res, é aquilo que resiste. Mas resiste a quê? Ao teste de força. Se, em dada situação, nenhum discordante é capaz de modificar a forma de um objeto novo, então sim, ele é realidade, pelo menos enquanto os testes de força não forem modificados (LATOUR, 2000, p. 155, grifos do autor).

As provas de força, portanto, somam-se aos demais princípios para assegurar a irredutibilidade, na medida em que desautoriza uma caracterização definitiva ou classificação do ator e da ação, assumindo a indeterminação destes em que pesem as dificuldades decorrentes, em termos metodológicos. Em vez de uma "teoria estável do ator" (CALLON, 1999, p. 181), percorrem-se os rastros de processos nos quais estão ausentes atores com propriedades fundamentais (CALLON, 1986), em meio à circulação de "identidades de geometria variável" (CALLON, 1999, p. 186). 


\subsection{Simetria Generalizada como Epistemologia da TAR}

Nesta subseção, o pressuposto do tratamento simétrico presente na TAR é discutido a partir de suas implicações epistemológicas, primeiro em função de sua oposição a perspectivas analíticas alicerçadas na divisão objetivo/subjetivo, tais quais o realismo empírico e o construtivismo. Segundo, a questão da simetria é abordada quanto à sua recusa em explicar tudo socialmente, isto é, sua exigência de um repertório básico, suficientemente aberto para capturar variações presentes no campo empírico sem limitar aprioristicamente os tipos de entidades existentes nas práticas dos atores.

\section{a) A problemática separação natureza-sociedade, construtivis- mo e realismo empírico}

Epistemologicamente, a TAR afirma que novas considerações devem ser feitas sobre a relação natureza e sociedade, enquanto dualidade da tradição sociológica a ser abandonada. Uma das principais afirmações é de que não há dois polos distintos (LATOUR, 2012). A exemplo da prática científica, conforme vem discutindo a TAR, não há um lado onde está o social, com os sociólogos, suas técnicas, meios e ferramentas para conhecer e, do outro, a natureza, com os cientistas naturais, seus experimentos, laboratórios e inscrições científicas. Essas diferenças são, para a TAR, inexistentes.

Esses polos são ocasionados, para a TAR, por um processo de purificação buscado pela ciência moderna (LATOUR, 1994a; LEE; BROWN, 1998). A purificação, nesse sentido, é o movimento de estabelecer esses dois grandes coletores, natureza e sociedade, pelos quais a diversidade de seres que permeiam o mundo são seletivamente separados, de modo que nada reste, em tese, entre esses dois mundos ou câmaras. As coisas naturais devem ficar de um lado, fechadas no que se conhece como natureza, e os humanos devem ser isolados do outro, pertencentes ao polo chamado de sociedade. O trabalho de purificação é sempre tornar algo, ou humano, para que possa ser posto no lado da sociedade, ou coisa, para que possa ser colocada do lado da natureza. Para Latour (1994a), quanto mais a modernidade se esforçou para purificar esses dois polos, tanto mais promoveu uma multiplicação intermediária de seres que não podem ser considerados nem humanos, nem naturais, mas ao 
mesmo tempo se aproximam, ora de um, ora de outro desses polos. Serres (1990) chamou esses seres existentes intermediários de quase-objetos. Latour (1994a) afirma que também podem ser considerados quase-sujeitos.

Para a TAR, por sua vez, é preciso concordar que o processo de purificação existe, embora como ponto de chegada, como estabilização e não como condição ou ponto de partida. Mas ele não está sozinho. Ele é somente mais um trabalho existente entre muitos que ocorrem entre os dois polos. Para Latour (1994a) há, no meio, um trabalho de mediação, mais amplo e que engloba, inclusive, a purificação. A mediação é o composto de práticas, ações e eventos situados no âmbito das relações e interações dos atores e que possibilitam descolamentos e mudanças, tanto na própria configuração desses atores e suas conexões, como nos espaços e tempos implicados em suas performances. A mediação, para Latour, é tudo o que acontece entre os pretensos polos da natureza e sociedade, inclusive o processo de purificação que os mantém (LATOUR, 1994a).

A ciência moderna, nessa concepção, pratica somente o trabalho de purificação e ignora o trabalho de mediação. A sociologia tradicional, por exemplo, seguindo a lógica moderna, segmenta a própria sociedade em diversos níveis, em um processo interno de purificação, e os analisa separadamente. A estratificação ocorre em níveis que vão desde o micro até o macro e os frameworks de análise dependem dos tamanhos desses níveis. Os níveis sociais, para a sociologia, são compostos por indivíduos, relações humanas e cultura. Os materiais, as técnicas e a natureza, como um todo, são somente apêndices úteis para as relações humanas e os desdobramentos sociais. Como consequência dessa forma de análise, passa a existir, sociologicamente, "sociedade", "ordem social", "prática social", "dimensão social", "estrutura social", entre outros conceitos que reforçam essa divisão e que foram úteis para explicar os "fatos sociais" da modernidade (LATOUR, 2012). Essa utilidade se deu, principalmente, ao se tornarem, cada um ao seu tempo, os diversos níveis de análise da Sociologia.

Para a TAR, por sua vez, não é possível distinguir diferentes dimensões entre micro e macro atores. Callon e Latour (1981) afirmam que "existe, é claro, macro e micro atores, mas a diferença entre eles 
é provocada pelas relações de poder e pelas construções de redes e escapa à análise presumir à priori que os macroatores são maiores ou superiores que os microatores" (CALLON; LATOUR, 1981, p. 280, tradução do autor). A argumentação é que os atores devem ser entendidos como redes, com capacidades de formar associações e dissociações. Para a TAR, "não há nada de específico na ordem social; [...] não existe nenhuma dimensão social, nenhum 'contexto social', nenhuma esfera distinta da realidade a que possa atribuir o rótulo 'social' ou 'sociedade'"' (LATOUR, 2012, p. 21).

Diferente do trabalho de purificação, que é uma consequência direta da atuação humana em classificar e organizar suas realizações, a mediação diz respeito às relações e interações de todos os pertencentes entre os supostos polos da natureza e sociedade. Os atores são tanto os humanos, como os não humanos; tanto os quase-objetos, como os quase-sujeitos, pois todos estão implicados relacionalmente, seja estabelecendo vínculos, seja sofrendo conexões de outrem. Nessa abordagem, tratar simetricamente os seres envolvidos nos fenômenos estudados em uma pesquisa exige contornar as perspectivas epistemológicas fundamentadas naquela divisão arbitrária. Isto é, exige encontrar alternativas tanto ao construtivismo social (que reconhece a priori a divisão e se limita à explorar subjetividades restritas ao polo social) quanto ao realismo empírico (que se apoia na mesma divisão para reivindicar explicações pelo acesso ao polo das coisas em si, em sua objetividade). Não se trata, porém, de uma tentativa de reconciliar a dicotomia sujeito-objeto nem de propor uma forma diferente de relação entre essas partes: "Não há relação alguma entre o 'mundo material' e o 'mundo social' justamente porque essa divisão é um completo artefato" (LATOUR, 2012, p. 113).

Em decorrência das redefinições presentes na TAR, não faz sentido considerar o pressuposto construtivista que enfatiza apenas os indivíduos humanos na construção da realidade social, tampouco pode-se assumir uma realidade independente, externa ou natural a ser explicada pelo realismo empírico. A possibilidade de existência de uma realidade não está nem polarizada do lado da natureza para que alguém ou alguma coisa possa ser considerado indiscutivelmente como real, nem é construída unicamente pela sociedade, para que 
possa ser desvendada pelo construtivismo (LATOUR, 1994a). Latour (1994a, p. 84) destaca que:

[...] Os que desejarem manter-se exatamente no meio [entre construtivismo e realismo] inventarão inúmeras combinações para separar a natureza da sociedade (ou sujeito), alternando a "dimensão simbólica" das coisas com a "dimensão natural" das sociedades. Outros, mais imperialistas, tentarão naturalizar a sociedade integrando-a na natureza, ou então socializar a natureza, fazendo com que seja digerida pela sociedade (ou, o que é mais difícil, pelo sujeito). Entretanto, estas referências e estes debates continuam a ser unidimensionais. Classificar todas as entidades segundo uma única linha que vai da natureza a sociedade seria o mesmo que elaborar mapas geográficos somente com a longitude, o que os reduziria a um único traço!

Para estudos ancorados na TAR, é preciso considerar certo relativismo diante da realidade, não se sujeitando cegamente nem ao realismo nem ao construtivismo, mas não os negando também em princípio. Os objetos, as coisas, os humanos e suas realizações e interações são concretas o suficiente para não serem ignorados ou que a possibilidade de conhecê-los precise ser colocada à prova, por isso não é possível desconsiderar o realismo como o fazem os construtivistas. Por sua vez, há fatos demais sendo continuamente construídos por uma infinidade de atores para que a construção da realidade possa ser igualmente colocada em dúvida. Certo relativismo, portanto, permite duvidar da generalidade das interações e orienta para as especificidades das relações.

Assim, o tratamento simétrico das entidades envolvidas em um fenômeno pesquisado não corresponde a qualquer forma de reconciliação referente à divisão sociedade/natureza, mas de abandonar esse recurso sob a forma de "uma dissolução conjunta de ambos os coletores" (LATOUR, 2012, p. 114).

\section{b) Estendendo o tratamento simétrico e a questão do vocabu- lário das explicações \\ A TAR, desse modo, ao superar as dualidades existentes entre diferentes e divergentes formas de entender a realidade, pressupõe}


que é necessário um "desapego" a conceitos tradicionais como verdade, racionalidade e objetividade tomados como indiscutíveis na ciência moderna (DOMÈNECH; TIRADO, 1998). A simetria é uma forma específica de conhecer a realidade baseada na superação desses pressupostos. Trata-se de uma recusa em explicar verdades por meio de termos que fazem referência a uma suposta objetividade de um mundo exterior, enquanto se explica o que seja tomado como falso por intermédio de termos completamente distintos, que fazem referência a subjetividades, crenças e símbolos, entre outros. Implica que uma explicação simétrica deve "conservar apenas as causas que poderiam servir tanto para o vencedor quanto para o vencido, para o sucesso e para o fracasso" (LATOUR, 1994, p. 93), sem recorrer a recursos distintos para explicar pontos de vista conflitantes (CALLON, 1986).

Esse conceito de simetria é atribuído, inicialmente, a David Bloor, em sua obra Conhecimento e Imaginário Social, datada originalmente de 1976, na qual o autor define o que deveria ser um programa forte para o desenvolvimento de uma sociologia do conhecimento. Seu argumento é que sociedade, economia, política, cultura e outras áreas estão totalmente entrelaçadas com os conteúdos científicos, devendo ser, portanto, analisados igual e conjuntamente. Com isso, é necessário considerar uma adequação de princípios que assegure equilíbrio nas análises. Para Bloor (2009), esses princípios devem estar ancorados na causalidade, imparcialidade, simetria e reflexividade, devendo o conhecimento ser tratado imparcial e simetricamente. O sentido de simetria torna-se relevante para que um mesmo estilo de explicação para os mesmos tipos de causas sirva para descrever tanto as questões tidas como verdadeiras quanto as falsas.

Para Latour e Woolgar (1997), é a partir do conceito de simetria de Bloor que se torna possível discutir no âmbito da TAR que humanos e não humanos devem ser tratados de maneira simétrica na construção dos fatos científicos. É a partir das argumentações de Bloor que a TAR vai tratar os efeitos da ciência de maneira simétrica sem rotulá-la, nem como social, nem tecnológica, já que, além de humanos, técnicas e objetos também estão envolvidos na sua composição. Isso, contudo, representa uma expansão do princípio 
da simetria em Bloor, o qual é tomado de modo similar, mas é ao mesmo tempo "consideravelmente estendido" (CALLON, 1986, p. 4).

A simetria define que as dualidades consideradas pela ciência, como verdade e erro, têm as mesmas origens, devendo, portanto, ser consideradas igualmente. Originalmente, em Bloor, esse princípio significou romper com a tradição de explicar os fenômenos científicos "desviantes" por meio de uma perspectiva sociológica, enquanto a prática científica considerada convencional e verdadeira não carecia de explicação, estando ela sancionada pela "realidade objetiva dos fatos". Contudo, Bloor tratou de submeter todas as práticas da ciência a uma mesma perspectiva, tratando erro e verdade simetricamente, buscando explicá-los pelo mesmo conjunto de causas: as sociais. Isto é, seu princípio poderia ser sintetizado na declaração de que "tanto o que é verdadeiro quanto o que é falso são explicados pela sociedade" (LATOUR, 1994, p. 94). Entretanto, como os autores da TAR observaram, na medida em que exclui o polo da natureza do processo explicativo, essa declaração ainda guarda algo de bastante assimétrico, questão resolvida apenas pelo recurso à simetria generalizada, que põe sociedade e natureza como algo a ser explicado em si, partindo dos híbridos, isto é, da ênfase na heterogeneidade dos coletivos e da sua livre associação, em vez da consideração prévia da separação em coletores distintos.

Isso implica dizer que sem coletores prévios distintos, logo, sem distinção no repertório básico utilizado para explicar as associações entre os híbridos. Para a TAR, tudo o que é realizado no trabalho de mediação deve ser tratado simetricamente. A simetria generalizada exige, assim, que o pesquisador "não altere seus registros quando se mover dos aspectos técnicos para os aspectos sociais dos problemas estudados" (CALLON, 1986, p. 4). As descrições precisam ser utilizadas da mesma forma para todos os elementos que compõem a rede. Nesse sentido, Law (1998, p. 66) afirma que "necessitamos de um vocabulário único quando descrevemos o trabalho de criação e imposição do social e o científico, e necessitamos também de uma maneira única, unificada, de falar a acerca dos êxitos e fracassos de tais intentos". Para Singleton e Michael (1998, p. 173), a simetria generalizada diz respeito ao "uso de um vocabulário abstrato e neutro para compreender os pontos de vista conflitivos dos atores". 
Generalizando-se a simetria, desse modo, aprofunda-se "um regime de emagrecimento para as explicações" (LATOUR, 1994, p. 93), já defendido por Bloor. Na mesma direção, um desapego às metalinguagens rebuscadas de explicações sociais que procuram traduzir os quadros de referência dos atores para uma linguagem comum é a proposta da TAR. Em vez de um "vocabulário padrão" ou "moeda corrente" (LATOUR, 2012, p. 62), busca-se empregar uma “infralinguagem" (LATOUR, 2012, p. 79) que possibilite atentar para as diferenças, para as variações presentes no repertório dos atores e as distintas entidades a que fazem referência.

Ao praticar a simetria generalizada para a obtenção de descrições com o máximo possível de imparcialidade, é preciso uma postura agnóstica (CALLON, 1986; DOMÉNECH; TIRADO, 1998) enquanto o pesquisador se move na rede de atores estudada. Uma postura agnóstica contribui para estudos simétricos, pois permite que todas as entidades humanas e não humanas e explicações racionais ou místicas possam ser levadas em consideração na análise, sem que ponto de vista algum seja privilegiado e interpretação alguma seja censurada. O pesquisador, de maneira agnóstica, pode seguir os atores e identificar a maneira como eles definem e associam os diferentes elementos, por meio dos quais os mesmos constroem e explicam os seus mundos (CALLON, 1986).

Não se pode confundir, contudo, simetria generalizada com as relações simétricas ou assimétricas das associações em si. A simetria generalizada não pressupõe que haja nas associações de atores uma simetria natural entre humanos e não humanos. Nem trata da equivalência ou não equivalência entre eles. Nem pretende, como diz Latour (2012, p. 113), pressupor uma "reconciliação da famosa dicotomia objeto/sujeito". A simetria é para "não impor a priori uma assimetria espúria entre ação humana intencional e mundo material de relações causais" (LATOUR, 2012, p. 114). Além disso, não se pretende unir natureza e sociedade para que permaneçam juntas nas explicações científicas, o que se busca é exatamente não incorrer em uma acentuação das purificações desses polos e evitar suposições de que esses sejam dotados de simetrias. A simetria generalizada, ao contrário, é recurso epistemológico que pressupõe simplesmente que "a continuidade de um curso de ação raramen- 
te consiste de conexões entre humanos [...] ou entre objetos, mas, com muito maior probabilidade, ziguezagueia entre umas e outras" (LATOUR, 2012, p. 113).

Com a simetria, desse modo, evita-se colocar o peso das explicações sobre um ou outro polo entre natureza e sociedade. O tratamento simétrico assegura que, se o analista for realista para uma, deve-se da mesma forma ser para a outra. Se for construtivista para uma, também deverá ser para a outra, não podendo empregar, por exemplo, um vocabulário de termos sociais para explicar "questões sociais", enquanto faz uso de termos completamente distintos para explicar "questões naturais" (LATOUR, 1994a, p. 95). Entretanto, ao abandonar os coletores sociedade-natureza e se concentrar na hibridez e heterogeneidade dos coletivos, nem o construtivismo nem o realismo empírico atendem ao requisito em questão, visto que estão assentados na grande divisão diluída pela TAR. Na simetria generalizada, então, o observador não se ocupa de um mundo dividido em polos, mas procura situar-se no emaranhado das relações.

[...] deve estar situado no ponto médio, de onde pode acompanhar, ao mesmo tempo, a atribuição de propriedades não-humanas e de propriedades humanas [...]. Não lhe é permitido usar a realidade exterior para explicar a sociedade, nem tampouco usar os jogos de poder para dar conta daquilo que molda a realidade externa. Também não lhe é permitido alternar entre o realismo natural e o realismo sociológico, usando "não apenas" a natureza, "mas também" a sociedade, a fim de conservar as duas assimetrias iniciais, ao mesmo tempo em que dissimula as fraquezas de uma sob as fraquezas da outra [...].

Ao analisar a realidade por meio da simetria generalizada, os deslocamentos e transformações realizados pelas associações são descritos a partir dos mesmos termos usados para todos os atores da rede. Essa condição é necessária, como visto, pois as translações não são deslocamentos negociados unicamente de maneira linear e amistosa. É preciso imparcialidade e agnosticismo com relação às verdades das argumentações que os atores empregam nas muitas controvérsias que se fazem presentes nas redes estudadas. 


\section{A TAR E OS ESTUDOS BRASILEIROS NA ÁREA DE ADMINISTRA- ÇÃO: UMA BREVE INCURSÃo POR ARTIGOS RECENTES}

Discutidos os pressupostos da irredutibilidade e da simetria, destacados na seção anterior, esta parte do trabalho pretende tornar mais visível algumas formas pelas quais a pesquisa em Administração no Brasil tem feito uso da TAR. Ao tempo em que esse esforço poderá permitir uma maior compreensão a respeito dos tópicos teórico-metodológicos que decorrem dos princípios explorados, também poderá propiciar clareza adicional sobre a relação da abordagem como temas de pesquisa bastante relevantes na área de administração, como mudança nas organizações; expansão tecnológica; empreendedorismo; gestão pública e; processos organizativos.

Os artigos selecionados para o propósito desta seção, além de atenderem ao critério de fazer uso teórico e/ou metodológico da TAR e versarem sobre temáticas administrativas/organizacionais, foram escolhidos pelo seu caráter recente (publicados pós 2010) e por contemplarem explorações empíricas em seus estudos. O último ponto, em especial, permite discorrer acerca da tarefa de operacionalizar as investigações, ponto delicado em qualquer projeto de pesquisa, especialmente quando se empregam abordagens pouco frequentes na literatura a respeito da área estudada. Dito isto, optou-se por enfatizar questões trazidas por cinco desses trabalhos (TURETA; ALCADIPANI, 2011; TURETA; ARAÚJO, 2013; TONELLI; ZAMBALDE, 2015; CERRETO; DOMENICO, 2016; VALADÃO; CORDEIRO NETO; ANDRADE, 2017), apresentando sobre eles as breves considerações a seguir:

a) $\mathrm{O}$ pesquisador no emaranhado das redes sociomateriais e os desafios na pesquisa sobre organizações

O trabalho de Tureta e Alcadipani (2011) permite uma reflexão bastante apurada a respeito de como o empreendimento de pesquisas em análise organizacional inspiradas pela abordagem da TAR apresenta particularidades tanto em termos da forma de exploração da temática sob investigação quanto, sobretudo, em termos da condução das técnicas de pesquisa empreendidas. Apresentando parte dos esforços de uma pesquisa que focaliza práticas de um tipo de 
organização considerada tipicamente brasileira, a escola de samba na cidade do Rio de Janeiro, Brasil, os autores possibilitam ao leitor uma demonstração da tarefa de multiplicar as entidades sob consideração em sua análise e de evitar divisões analíticas prévias.

Ao se concentrar sobre as dificuldades em conduzir estratégias de caráter etnográfico para a análise organizacional, os pesquisadores mostram como as fronteiras entre a técnica da observação participante e da observação não participante tornam-se problemáticas de serem administradas em função dos eventos que se desenvolvem durante o trabalho de campo. $\mathrm{O}$ artigo mostra como, no campo analisado, sacolas, adereços de fantasias, profissionais do carnaval, carros alegóricos, códigos, plateias, uniformes e acidentes participam de situações que redefinem a todo momento o indivíduo que conduz a pesquisa, levando-o a configurações nas quais ele não tem controle completo de suas funções e da técnica de observação praticada.

b) Dualismos comuns no estudo das organizações e a ideia de organização sem fronteiras

Em Tureta e Alcadipani (2013), por sua vez, a TAR como inspiração é menos evidente, apesar de os autores recorrerem com certa frequência à abordagem para reforçarem sua opção por uma perspectiva de investigação que fuja de dicotomias tradicionalmente empregadas quando da análise de seu objeto de estudo. Eles se referem mais uma vez às escolas de samba e aos trabalhos que as interpretam a partir de binômios como tradição/modernidade; popular/empresarial; interno/externo; autêntico/invasivo; central/ periférico, entre outros.

Recorrendo a uma análise das práticas organizativas em torno das escolas de samba, em perspectiva histórica, esse trabalho permite visualizar como uma grande variedade de elementos muito heterogêneos (políticas, estilos musicais, movimentos intelectuais, grupos, organizações turísticas, rádios e TVs, técnicas de gestão etc.) associaram-se de formas distintas ao longo do tempo e estabilizaram sempre parcialmente - e de diferentes maneiras ao longo desse percurso - o que pode ser entendido como escola de samba. Isso permite, desse modo, questionar sobre o que vem a ser essencial, genuíno, interno, central em uma escola de samba e explorar 
oportunidades analíticas sob o prisma da noção de organizações sem fronteiras para esse objeto de estudo.

\section{c) Controvérsias, estabilização de objetos e o empreendedo- rismo de base tecnológica}

Tonelli e Zambalde (2015) buscam na TAR recursos teóricos para compreender o campo de estudo que exploram, qual seja as atividades de instituições públicas de ciência e tecnologia e suas relações com o setor privado, no âmbito do que a literatura veio a denominar pelo termo empreendedorismo de base tecnológica. Em vez de partir de metanarrativas sobre o público, o privado e a relação Estado-Sociedade, os autores voltam-se nessa publicação para a investigação sobre os instrumentos normativos que devem disciplinar tal relação no Estado de Minas Gerais, Brasil. Procuram, em vez de tomá-los como entidades fechadas, abordar o processo que levou à formatação deles, enfatizando, desse modo, as controvérsias do que entendem como fase de pré-estabilização dos objetos.

Os pesquisadores fazem uso de procedimentos metodológicos que envolvem documentos, entrevistas e técnicas observacionais, para a coleta e produção de dados que foram analisados sob orientações advindas da tradição de pesquisa da Grounded Theory. Na discussão apresentada pelo trabalho, o leitor pode compreender como o empreendedorismo de base tecnológica, longe de mostrar-se como elemento definido e previsível, compreende processos organizativos instáveis e imprevisíveis, em decorrência da grande variedade de elementos que circulam nas controvérsias que antecedem a estabilização de sua configuração normativa.

\section{d) A implantação de um Centro de Serviços em uma empresa de economia mista}

Cerreto e Domenico (2016) tratam do tema da mudança nas organizações, dedicando-se especificamente ao processo de implantação de uma nova modalidade de prestação de serviços por parte de uma empresa de economia mista, no Estado de São Paulo, Brasil. O trabalho mostra como a pesquisa optou por abordar o tópico em estudo a partir da chamada ontologia de fluxos em vez da preferência tradicional pela ontologia de substâncias. Com isso, a TAR 
é recrutada para o esforço de tratar a transformação para além da concepção de mudança planejada, mediante a qual o novo Centro de Serviços seria apenas uma consequência instrumentalizada em resposta a propósitos organizacionais claros.

A investigação teve caráter etnográfico com observação participante, relacionando também pesquisa documental e entrevistas. Os autores observam que, ao longo de 14 meses de acompanhamento do processo pesquisado, centenas de questões conflitantes entre os atores puderam ser identificadas. Além disso, apontam que após esse período, das dezenas de pontos mais relevantes entre essas controvérsias, apenas um terço havia chegado a termos estáveis, ainda que provisoriamente (fechamento de caixas-pretas). Isso permite a compreensão de que o centro implantado até aquele momento era muito parcialmente uma realização determinada por planejamento, mostrando-se empiricamente mais como uma forma de ordenamento das atividades, um efeito precário cuja configuração poderia ser significativamente modificada na medida do desenrolar dos conflitos ainda em aberto. Além disso, a existência de tantas controvérsias, por si, permite compreender a opção da pesquisa em evitar orientar-se pela ideia de "mudança planejada a partir de propósitos pré-definidos".

\section{e) A expansão de uma tecnologia social em educação do campo}

O processo de expansão de uma tecnologia social denominada por Pedagogia da Alternância, adotada em milhares de escolas rurais em todo o mundo e por centenas de escolas de áreas rurais brasileiras, é estudado por Valadão, Cordeiro Neto e Andrade (2017), tomando como campo empírico tal expansão no Estado de Rondônia, na região Norte do Brasil. A TAR é tomada como orientação teórico-metodológica no trabalho e associada à literatura sobre tecnologias sociais e adequação sociotécnica, com o propósito de caracterizar as formas de envolvimento dos diferentes atores presentes na dinâmica investigada, bem como compreender como tais envolvimentos repercutiram nas características tomadas pelo processo de expansão.

A pesquisa tomou a observação participante como uma das principais formas de coleta de dados, além da análise de fontes documentais e da complementação via entrevistas. Concentrando-se 
sobre o conceito de translações presentes nas controvérsias desenvolvidas no campo, os autores procuram mostrar como a tecnologia social em questão foi adotada por um número cada vez maior de escolas rurais em diferentes áreas do Estado, porém, sem as padronizações consideradas desejáveis por alguns dos atores, notadamente pelo Governo local. Interpretam, assim, que as dinâmicas específicas em torno de cada momento da expansão transladaram, com mediações e mudanças, a tecnologia em questão, em vez de a terem apenas transportado, com meras intermediações e traduções fiéis.

\section{CONSIDERAÇõeS FINAIS}

Ao propor sua reelaboração das ciências sociais, a Teoria do Ator-Rede possibilitou formas pouco usuais de abordagem de questões recorrentes na literatura, a exemplo das relações sujeito-objeto, estrutura-agência, micro-macro, técnico e social, entre outras. Quase sempre, as inovações sugeridas não consistem em reconciliar os polos presentes nessas dicotomias, mas em evitar as presilhas ontológicas e epistemológicas que esses artifícios impõem sobre as pesquisas que os tomam como recurso analítico a priori, como orientação para o trabalho empírico a ser desenvolvido. Entre as proposições da TAR, o presente trabalho procurou enfatizar dois pressupostos fundamentais de sua crítica ao chamado "Acordo Moderno" que caracterizaria o discurso da Ciência: a proposição da irredutibilidade e do tratamento simétrico.

Conforme discutido na seção 2, a ideia de irredutibilidade corresponde a uma posição ontológica que nega a fixação de identidades às entidades que compõem o mundo e, com isso, recusa o trabalho de equipará-los em conformidade com supostas essências, de compará-los, agregá-los em categorizações uniformes ou reduzi-los um aos outros. Em vez de uma existência alicerçada sobre essências, essa teoria pressupõe existências decorrentes de associações entre entidades diversas, seres relacionais formados a partir das conexões entre outras entidades e existentes apenas conforme a durabilidade dessas associações em estabilizações parciais. Associações distintas, portanto, existências distintas e irredutíveis umas às outras.

Por sua vez, o pressuposto da simetria generalizada pode ser compreendido como a exigência de não incorrer em posiciona- 
mentos epistemológicos que, como ponto de partida, dividam os seres em purificações estanques (natureza e sociedade) e passem a explicá-los mediante repertórios distintos que reforçam tal artifício de separação. Ainda, o tratamento simétrico na TAR ultrapassa as tentativas de reduzir as assimetrias por meio da simples tentativa de explicar ambos os polos por intermédio do repertório moderno elaborado para apenas um deles. Isto é, a generalização da simetria impede tal transposição (como se pode pretender com a ideia de que a natureza também deve ser socialmente explicada, pelo repertório desenvolvido para as questões ditas sociais). O pressuposto em tela advoga o desenvolvimento de um repertório básico, desacoplado da separação natureza/sociedade; Objeto/Sujeito; Técnico/Social, uma infralinguagem básica a ser empregada na descrição de todos os elementos identificados como relevantes em um fenômeno, independentemente, sejam humanos ou não humanos.

Com essas e outras particularidades, a TAR confere a possibilidade de utilização de renovados recursos teórico-metodológicos para diversos campos de investigação nas ciências sociais, motivo pelo qual tem havido crescente interesse a seu respeito. $\mathrm{O}$ campo dos estudos em Administração/Organizações, como assinalado na introdução deste artigo não ficou ausente nesse interesse pela TAR. Todavia, fazer uso de perspectivas como essa em áreas tradicionalmente caracterizadas pelo predomínio de orientações funcionalistas ou reducionistas também traz desafios consideráveis. Ainda que timidamente, alguns estudos brasileiros possibilitam compreender um pouco mais esse cenário, algumas de suas possibilidades e até mesmo de suas complexas exigências.

Partindo dos cinco estudos brasileiros brevemente discutidos na seção anterior, algumas formulações parecem possíveis de serem inicialmente delineadas. Aqui, ressaltam-se quatro delas. Primeiro a variedade de temas encerrados nesse pequeno conjunto de trabalhos pode ser um claro estímulo à incorporação da TAR na investigação de temáticas administrativas/organizacionais. Isso pode ser dito em função da insistência da teoria em manter-se longe de determinações prévias sobre o comportamento dos atores envolvidos em cada fenômeno, buscando prioritariamente garantir abertura à variedade de configurações possíveis nas práticas. 
Em segundo lugar, é notório que todos os trabalhos façam uso da TAR em combinação com alguma perspectiva teórica de maior consolidação no campo dos estudos em administração/organizações: seja, por exemplo, a concepção de organização sem fronteiras em Tureta e Araújo (2013); a literatura sobre empreendedorismo em Tonelli e Zambalde (2015); a mudança organizacional e processos organizativos em Cerreto e Domenico (2016); e o tema das tecnologias sociais e da adequação sociotécnica em Valadão, Cordeiro Neto e Andrade (2017). A TAR está geralmente empregada com o intuito de possibilitar uma investigação mais livre e renovada sobre temáticas tradicionalmente abordadas mediante enquadramentos analíticos mais rígidos.

Terceiro, quase sempre esses estudos fazem uso de estratégias metodológicas com bastante abertura para a indução, por meio de uma ênfase significativa em práticas, daí que orientações etnográficas e o uso de técnicas observacionais sejam frequentes, a exemplo de Tureta e Alcadipani (2011); Tonelli e Zambalde (2015); Cerreto e Domenico (2016); e Valadão, Cordeiro Neto e Andrade (2017). Metodologicamente, também se observa certa associação de princípios da TAR com proposições mais consagradas na área de estudos, o que demanda atenção a fim de salvaguardar a coerência com a abertura ao empírico presente na TAR, como se observa na opção pela Grounded Theory em Tonelli e Zambalde (2015) e pelo estudo de caso em Valadão, Cordeiro Neto e Andrade (2017), para citar alguns. Ainda nesse tópico, também chama atenção que o termo controvérsias mostre-se fundamental para a sistematização metodológica nos trabalhos de Tonelli e Zambalde (2015); Cerreto e Domenico (2016) e Valadão, Cordeiro Neto e Andrade (2017). Trata-se de um conceito primordial desde o início da TAR (CALLON, 1986; LATOUR, 1994) e que recentemente tem sido defendido como central para os estudos por ela orientados, ensejando o desenvolvimento de perspectivas metodológicas próprias como o mapeamento de controvérsias (VENTURINNI, 2010a; 2010b), o qual foi empregado como tal por Cerreto e Domenico (2016). Isso, acredita-se, está a indicar que discussões sobre o conceito de controvérsias, suas implicações e possibilidades para a prática de pesquisa, mostram-se bem-vindas entre os pesquisadores, pelas oportunidades que abrem para elaborar formas de investigação operacionalizáveis em diversas temáticas. 
Em quarto lugar, cabe por fim destacar que os estudos brasileiros abordados demonstram como o emprego da TAR faz-se acompanhar da irredução, tornando visível a diversidade dos atores envolvidos nos fenômenos pesquisados (de alegorias de carnaval a pautas de reuniões e e-mails de gestores; de documentos normativos a imprevistos e acidentes; de governos a plateias), desde que não se delimite de antemão qual a categoria de agentes de interesse para o trabalho de exploração do campo empírico. Também, a ênfase nas inúmeras possibilidades de configuração dessas associações, pelo tratamento simétrico das entidades envolvidas, proporciona ser sensível às diferenças e enxergar mudanças onde leituras convencionais poderiam ver apenas reproduções. Isso pode ser compreendido quando os trabalhos enfatizam questões como as transformações vividas pelo pesquisador a depender de suas associações com humanos e/ ou não humanos no decorrer de um trabalho de campo (TURETA; ALCADIPANI, 2011); as diferentes formas de estabilização parcial dos elementos que constituem uma escola de samba ao longo do percurso histórico analisado (TURETA; ARAÚJO, 2013); o entendimento de que a configuração daquilo denominado por empreendedorismo depende de uma incerta estabilização de objetos, num processo que envolve diversas visões conflitivas (TONELLI; ZAMBALDE, 2015); a evidenciação de que um Centro de Serviços implantado constitui mudança na organização estudada, porém, sob uma dinâmica de controvérsias que à medida que vão se desenvolvendo tendem a alterar o Centro implantado com maiores ou menores desvios em relação ao que fora a mudança planejada (CERRETO; DOMENICO, 2016); e a conclusão de que a expansão de uma tecnologia social no interior de uma unidade administrativa permite visualizar diferentes tecnologias, a depender das diversas relações desencadeadas pelos atores quando da sua implantação em distintas localidades (VALADÃO; CORDEIRO NETO; ANDRADE, 2016).

Portanto, as considerações em tela explicitam motivos razoáveis para que se creditem à TAR oportunidades desejáveis de inovação nos estudos do campo de administração/organizações. Tais oportunidades podem ser ressaltadas quando de um adequado atendimento aos pressupostos de irredutibilidade e de simetria generalizada, razão pela qual espera-se que novos trabalhos venham a empreender 
o desafio de tomá-los como orientação para a pesquisa em variadas temáticas, de modo criativo e criterioso. Semelhantemente, trabalhos de natureza teórica também podem proporcionar desdobramentos relevantes para a compreensão e para a prática de pesquisadores que utilizam ou desejem utilizar a TAR em seus estudos.

\section{REFERÊNCIAS}

ALCADIPANI, R.; HASSARD, J. Actor-network theory, organizations and critique: towards a politics of organizing. Organization, v. 17, n. 4, p. 419-345, 2010.

ALCADIPANI, R.; TURETA, C. Teoria Ator-rede e análise organizacional:

contribuições e possibilidades de pesquisa no Brasil. Organizações \& Sociedade, v. 16, n. 51, p. 647-664, 2009.

ANDRADE, J. A. What holds us together? Analyzing Biotech field formation. J. Technol. Manag Innov., v. 6, n. 3, 2011, p. 1-12.

ANDRADE, J. A. Redes de atores: uma nova forma de gestão das políticas públicas no Brasil? Gestão e Regionalidade, n. 64, p. 52-66, 2006.

ANDRADE, J. A. Actor-Network Theory (ANT): uma tradução para compreender o relacional e o estrutural nas redes interorganizacionais? Cadernos EBAPE. Rio de Janeiro, v. 2, n. 4, 2004. AUlETE, Digital. Dicionário contemporâneo da Língua Portuguesa. Disponível em: www.aulete.com.br. Acesso em 18 de agosto de 2012.

ANDRADE, J. A.; CORDEIRO NETO, J. R.; VALADAO, J. A. D. Associações sociotécnicas e práticas de gestão em desenvolvimento: analisando rastros por entre o traçado do P1MC. Cadernos EBAPE.BR (FGV), v. XI, p. 274-294, 2013.

ARNABOLDI M., AZZONE G. (2010). Constructing performance measurement in the public sector. Critical Persp. Account. 21: 266-282.

BIJKER, W. E. Do not despair: there is life after constructivism. Science, Technology \& Human Values, v. 18, n. 1. Winter, 1993, p. 113-138.

BIJKER, W. E., HUGHES, T. P., PINCH, T. (Orgs.). The Social Construction of Technological Systems: New Directions in the Sociology and History of Technology. The MIT Press, Cambridge, Massachusetts, 1987.

BLOOR, David. Conhecimento e imaginário social, 2. ed. São Paulo: UNESP, 2009.

CALLON, M. Actor-network theory - the market test. In: LATOUR, B. In: LAW, J.; HASSARD, J. Actor-network theory and after. Oxford: Blackwell Publishing, 1999, p. 15-25.

CALLON, M. Some elements of a sociology of translation: domestication of the scallops and the fishermen of St Brieuc Bay. In: LAW, J. Power, action and belief: a new sociology of knowledge? London: Routledge, 1986, p. 196-223.

CALLON, M.; LATOUR, B. Unscrewing the big leviathan: how actor macro-structure reality and how sociologists help them to do so. In: KNORR-CETINA, K.; CICOUREL, A. V. Advances 
in social theory and methodology: toward an integration of micro and macro-sociologies. Boston: Routledge \& Kegan, 1981, p. 277-303.

CAMILLIS, P. K.; ANTONELLO, C. S. Da translação para o enactar: contribuições da Teoria Ator-Rede para a abordagem processual das organizações. Cad. EBAPE.BR, v. 14, n. 1, Artigo 4. Rio de Janeiro, jan./mar. 2016.

CAMILLIS. P. K.; BUSSOLAR, C. Z.; ANTONELLO, C. S A agência a partir da Teoria Ator-Rede: reflexões e contribuições para as pesquisas em administração. Organizações \& Sociedade, v. 23, n. 76, p. 073-091, jan./mar. 2016.

CAVALCANTI, M. F. R.; ALCADIPANI, R. Organizações como processos e Teoria Ator-Rede: A contribuição de John Law para os Estudos Organizacionais. Cad. EBAPE.BR, v. 11, n. 4, artigo 4. Rio de Janeiro, dez. 2013.

CERRETO, C. DOMENICO, S. M. Mudança e Teoria Ator-Rede: Humanos e Não Humanos em Controvérsias na Implementação de um Centro de Serviços Compartilhados. Cad. EBAPE. BR, v. 14, no. 1, Artigo 5. Rio de Janeiro, jan./mar. 2016.

CORDEIRO NETO, J. R.; VALADÃO, J. A. D.; ANDRADE, J. A. Análise de Redes Sociais, Suas Limitações e Recursos Teóricos para uma Abordagem Relacional nos Estudos Organizacionais. In: Anais do XL Encontro Nacional da ANPAD_Enanpad, 2016,

CZARNIAWSKA, B. Emerging institutions: pyramids or anthills? Organization Studies, v. 30, n. 4, 2009, p. 423-441.

CZARNIAWSKA, B. STS Meets MOS. Organization, 2009b, v. 16(1): 155-160.

DELEUZE, G.; GUATTARI, F. A thousand plateaus: capitalism and schizophrenia. Minneapolis: University Minnesota Press, 1987.

DOMÈNECH, M. TIRADO, F. J. Sociología simétrica: ensayos sobre ciencia, tecnología y sociedad. Barcelona: Gedisa Editorial, 1998.

DUARTE, M. F.; ALCADIPANI, R. Contribuições do organizar (organizing) para os estudos organizacionais. Organizações e Sociedade, v. 23, n. 76, p. 057-072, jan./mar. 2016.

DUSEK, V. Philosophy of technology: an introduction. Oxford: Blackwell Publishing, 2006.

FELDMAN, M. S.; ORLIKOWSKY, W. J. Theorizing practice and practicing theory. Organization Science, v. 22, n. 5, p. 1.240-1.253, 2011.

FOUCAULT, M. Vigiar e punir: nascimento da prisão. Petrópolis: Vozes, 1987.

GARFINKEL, H. Studies in ethnomethodology. New Jersey: Prentice Hall, 1967.

GREIMAS, A. J.; COURTÉS, J. Dicionário de semiótica. São Paulo: Cultrix, 1979.

HARMAN, G. Technology, objects and things in Heidegger. Cambridge Journal of Economics, n. 34, 2009, p. 1-9.

HASSARD, J.; COX, J. W. Can sociological paradigms still inform organizational analysis? A paradigm model for post-paradigm times. Organization Studies, 2013, 34(11): 1.701-1.728.

HUGHES, T. Networks of power: electrification in Western Society, 1880-1930. Londres: Johns Hopkins University Press, 1983. 
The evolution of large technological systems. In: BIJKER, W. E., HUGHES, T. P., PINCH, T. (Orgs.). The social construction of technological systems: new directions in the sociology and history of technology. The MIT Press. Cambridge, Massachusetts, 1987. p. 51-82. LATOUR, B. The pasteurization of France. EUA: Harvard University Press, 1988a.

. A relativistic account of Einstein's Relativity. Social Studies of Science, América do Norte, v. 18, n. 1, p. 3-44, fev. 1988b.

. "Where are the missing masses? The sociology of a few mundane artifacts." In: BIJKER, W. E.; PINCH, T. F.; LAW, L. (Orgs.). Shaping technology/building society: studies in sociotechnical change. Cambridge: Mass. MIT Press, 1992, p. 225-258.

1994a.

. Jamais fomos modernos: ensaio de antropologia simétrica. Rio de Janeiro: Ed. 34,

. On technical mediation - philosophy, sociology, genealogy. Common knowledge, fall. Geórgia, v, 3, n. 2, p. 29-64, 1994b.

. La tecnología es la sociedade hecha para que dure. In: DORMÈNECH, M.; TIRADO, F. J. Sociología simétrica: ensayos sobre ciencia, tecnología y sociedad. Barcelona: Gedisa Editorial, 1998, p. 109-142.

. On recalling ANT. In: LAW, J.; HASSARD, J. (Orgs.). Actor-Network Theory and after. The Sociological Review. Oxford: Blackwell Publishers, 1999, p. 15-25.

Ciência em ação: como seguir cientistas e engenheiros sociedade afora. São Paulo: UNESP, 2000.

. A esperança de pandora: ensaios sobre a realidade dos estudos científicos. São Paulo: EDUSC, 2001.

. Políticas da natureza: como fazer ciência na democracia. São Paulo: EDUSC, 2004a.

. Entrevista: por uma antropologia do centro. MANA. Rio de Janeiro, v. 10, n. 2, p. 397-414, 2004b.

Reagregando o social: uma introdução à teoria do Ator-Rede. Salvador: EDUFBA, 2012.

LATOUR, B. On recalling ANT. In: LAW, J.; HASSARD, J. Actor-network theory and after. Oxford: Blackwell Publishing, 1999, p. 15-25.

LATOUR, B.; WOOLGAR, S. A vida de laboratório: a produção dos fatos científicos. Rio de Janeiro: Relume Dumará, 1997.

LAW, J. On the methods of long-distance control: vessel, navigation and the Portuguese rout to India. In: LAW, J. Power action and believe: a new sociology of knowledge? Heley: Routladge (sociological Review Monografh, 32), 1986.

. Notes on the theory of the actor network: ordering, strategy and heterogeneity. Centre for Science Studies, 1992, p. 1-11.

LAW, J.; Mol, A. (1995). "Notes on Materiality and Sociality." The Sociological Review, 43: 274-294. Del poder y suas tácticas: un enfoque desde la sociología de la ciencia. In: 
DORMÈNECH, M. TIRADO, F. J. Sociología simétrica: ensayos sobre ciencia, tecnología y sociedad. Barcelona: Gedisa Editorial, 1998, p. 63-108.

LAW, J. After ANT: complexity, naming and topology. In: LAW, J.; HASSARD, J.

Actor-network theory and after. Oxford: Blackwell Publishing, 1999.

. Actor-Network Theory and material semiotics. Lancaster University, 2007, p. 1-21. Disponível em: http://www.heterogeneities.net/publications/Law2007ANTandMaterial Semiotics.pdf, acesso em 24 de maio de 2012.

LEE, N.; BROWN, S. La alteridad y el actor-red: el continente no descubierto. In: DORMÈNECH, M. TIRADO, F. J. Sociología simétrica: ensayos sobre ciencia, tecnología y sociedad. Barcelona: Gedisa Editorial, 1998, p. 219-248.

LEE, N.; HASSARD, J. Organization unbound: Actor-network theory, research strategy and institutional flexibility. Organization, v. 6, n. 3, p. 391-404, 1999.

MACKENZIE, D. WAJCMAN, J. The social shaping of technology. Buckingham: Open University Press, 1999.

MOL, A. M. LAW, J. Embodied Action, Enacted Bodies: The Example of Hypoglycaemia. Body \& Society, v. 10 (2-3): 43-62.

MOSER, I.; LAW, J. Good passages, bad passages. In: HASSARD, J. (Orgs.). Actor-Network Theory and after. The Sociological Review. Oxford: Blackwell Publishers, 1999, p. 196-219.

ORLIKOWSKI, W. J.; SCOTT, S. V. Sociomateriality: challenging the separation of technology, work and organization. The Academy of Management Annals, v. 2, n. 1, p. 433-474, 2008.

$\mathrm{PINCH}, \mathrm{T}$. F. On making infrastructure visible: putting the non-humans to rights. Cambridge Journal of Economics, v. 34, 2010, p. 77-89.

PINCH, T. F.; BIJKER, W. E. The social construction of facts and artifacts: or how the sociology of science and the sociology of technology might benefit each other. In: BIJKER, W. E.; HUGHES, T. P.; PINCH, T. F. (Orgs.). The social construction of technological systems. Cambridge: Massachussetts Institute of Technology, 1987, p. 17-50.

SERRES, M. Hermes: uma filosofía da ciência. Rio de Janeiro: Graal, 1990.

Genesis. Michigan: The University of Michigan Press, 1995.

Dialógo sobre a ciência, a cultura e o tempo. Lisboa: Instituto Piaget, 1996.

. The bird of physics. Manchester: Clinamen Press, 2000.

SINGLETON, V. MICHAEL, M. Actores-red e ambivalencia. Los médicos de familia en el programa británico de citología de cribaje. In: DORMÈNECH, M. TIRADO, F. J. Sociología simétrica: ensayos sobre ciencia, tecnología y sociedad. Barcelona: Gedisa Editorial, 1998, p. 171-218.

STRUM, S. S.; LATOUR, B. Redefining the social link: from baboons to humans. London: Social Science Information, v. 26, n. 4, 1987, p. 783-802.

TONELLI, D. F. Origens e afiliações epistemológicas da Teoria Ator-Rede: implicações para a análise organizacional. Cad. Ebape, v. 14, n. 2, abr./jun. 2016, p. 377-390. 
TONELLI, D. F.; ZAMBALDE, A. L. Empreendedorismo de base tecnológica no contexto das instituições públicas de pesquisa em minas gerais: influências da pré-estabilização de objetos. Interciencia, v. 40, n. 2, febrero, 2015, p. 76-83.

TURETA, C.; ALCADIPANI, R. Entre o Observador e o Integrante da Escola de Samba: os Não-Humanos e as Transformações Durante uma Pesquisa de Campo. RAC, Curitiba, v. 15, n. 2, art. 3, p. 209-227, mar./abr. 2011.

TURETA, C.; ARAÚJO, B. F. V. B. Escolas de samba: trajetória, contradições e contribuições para os estudos organizacionais, v. 20, n. 64, p. 111-129, jan./mar. 2013.

VALADÃO, J. A.; CORDEIRO NETO, J. R.; ANDRADE, J. A. Bases sociotécnicas de uma tecnologia social: o transladar da Pedagogia da Alternância em Rondônia. Organizações \& Sociedade (On-line), v. 24, p. 89-114, 2017.

VENTURINI, T. Diving in magma: how to explore controversies with actor-network theory. Public Understand. Sci. 19(3), (2010a) 258-273.

VENTURINI, T. Building on faults: how to represent controversies with digital methodsPublic Understanding of Science. 20(10), 2010b, 1-17.

Recebido em: 11-4-2017

Aprovado em: 30-08-2017

Avaliado pelo sistema double blind review.

Editor: Elmo Tambosi Filho

Disponível em http://mjs.metodista.br/index.php/roc 